\title{
Cross-National Variations in the Correlation between Frequency of Prayer and Health among Older Europeans
}

Karsten Hank and Barbara Schaan

$115-2007$

๑ $\boldsymbol{m e a - M a n n h e i m ~ R e s e a r c h ~ I n s t i t u t e ~ f o r ~ t h e ~ E c o n o m i c s ~ o f ~ A g i n g ~}$ 


\title{
Cross-National Variations in the Correlation between Frequency of Prayer and Health among Older Europeans
}

\author{
Karsten Hank ${ }^{\mathrm{a}}$ and Barbara Schaan ${ }^{\mathrm{b}}$
}

February 2007

\begin{abstract}
This research investigates the relationship between private religious involvement, measured by the individual's frequency of prayer, and various dimensions of older adults' physical and mental health in nine European countries. Using data from the 2004 'Survey of Health, Ageing and Retirement in Europe' (SHARE), we estimate pooled and regional multivariate logistic regression models for four dependent variables: self-perceived general health, general physical health, functional limitations, and mental health. Our results suggest that private religious involvement among the population aged 50 or older is negatively correlated with all four health outcomes in the analysis. Moreover, we detect only minor cross-national variations in the prayer-health nexus within continental Europe. Although the cross-sectional nature of our data prohibits any statements about possible causal relationships underlying the observed correlations, the evidence presented here suggests that religion should be considered as a potentially relevant factor in future studies of older European's health.
\end{abstract}

\footnotetext{
${ }^{a}$ MEA - University of Mannheim \& DIW Berlin.Email: hank@mea.uni-mannheim.de.

b MEA - University of Mannheim. Email: schaan@mea.uni-mannheim.de.
} 


\section{Introduction}

The number of studies addressing the role of religion in health increased substantially during the past two decades (e.g., Aukst-Margetic and Margetic 2005; George et al. 2002; Weaver et al. 2004). A particularly relevant subpopulation for such kind of analyses are elders, whose share in the total population is not only growing rapidly, but who are also the ones who tend to exhibit the highest levels of religious involvement and who are affected the most by health problems (e.g., Idler 1987; McFadden 1995; Weaver et al. 2005). This paper complements the so far almost exclusively U.S. centered literature by providing a comprehensive account of cross-national variations in the correlation between religiosity and health among the population aged 50 or older in Europe. Drawing on data from the 2004 'Survey of Health, Ageing and Retirement in Europe' (SHARE), we investigate the relationship between private religious involvement - namely individuals' frequency of prayer - and various dimensions of older adults' physical and mental health in nine continental European countries.

Although the assumption of a general trend towards greater secularization has been challenged (e.g., Greeley 2003), the European public is unlikely to score as high on leading religious indicators as the U.S. population does (e.g., Princeton Religious Research Center 1999). Moreover, studies from Scandinavian countries suggest that the role of religion in survival and coping with illness might be lower there than in the United States (cf. Cederblad et al. 1995; la Cour et al. 2006; Ringdal 1996). However, our study is the first to investigate the religion-health nexus in a representative sample of European elders and to contrast these findings with evidence from U.S. research. A further major issue addressed in our study is, whether the strength and/or the direction of the proposed individual-level relationship between prayer and health outcomes varies across the diverse 'religious regimes' in Europe, where, for example, some countries show high levels of formal religious affiliation, others have high levels of active religious participation, and yet others might be low on both but 
may still not have abandoned religion (cf. Campbell and Curtis 1994; Voas 2004; Wolf 2005).

The next section briefly reviews previous empirical evidence about associations between religion and physical as well as mental health (especially functional limitations and depression) and discusses the mechanisms underlying the potential relationship between private prayer and health. Then we introduce our data, followed by a detailed presentation of (multivariate) descriptive findings from logistic regression models. The final section concludes.

\section{Previous research on the religion-health connection:}

\section{Empirical evidence and explanatory mechanisms}

In studies dealing with religiosity and physical health among the elderly, functional limitations should be a particular concern because of their relatively high prevalence and their potentially serious consequences for the individual's ability to cope with everyday activities and to live independently (cf. Benjamins 2004). There is clear cross-sectional and longitudinal evidence for an inverse relationship between church attendance and levels of functional disability (e.g., Benjamins 2004; Idler and Kasl 1997). This relationship appears to be very stable within the elderly population, that is, no significant age or sex differentials have been observed. Correlations between private religiousness and disability, however, sometimes even suggest more limitations among more religious elders. This finding could not be shown to be stable, though, and there are no apparent explanations for such an effect (see Benjamins 2004; Idler and Kasl 1992, for example). - Religious beliefs and activities have also been suggested to be associated with better immune function, lower death rates from cancer, less heart disease or better cardiac outcomes, as well as lower blood pressure and lower cholesterol (Koenig 2004: 1195). 
There seems to be some consensus that higher levels of religiosity may be inversely associated with the prevalence of depression scores and other measures of mental health (cf. Hackney and Sanders 2003; Koenig and Larson 2001; McCullough and Larson 1999), particularly among older religious adults (e.g., Kennedy at al. 1996; Norton et al. 2006). Different kinds of religious involvement appear to be more or less strongly associated with mental health, though, and studies pointing to such differences are difficult to compare. On the one hand, Hackney and Sanders (2003: 51) conclude from a meta-analysis of 34 studies that "an overall pattern can be seen in which using institutional religiosity as the defining characteristic produces the weakest (and the only negative) correlations [... with psychological adjustment ...], and personal devotion producing the correlations of greatest magnitude." McCullough and Larson's (1999: 134) review of 80 studies, on the other hand, suggests that people "who are involved frequently in organized religion and who highly value their religious faith for intrinsic reasons are at a substantially reduced risk of depressive disorder and depressive symptoms. [...] Conversely, people who are involved in religion for reasons of self-interest are at a decidedly higher risk for depressive symptoms. [Moreover, ...] particularly private religious activities and religious beliefs [appear] to bear no lawful association with measures of depression". A robust finding seems to be that Jews and people with no religious affiliation are at elevated risks of depressive symptoms (e.g., Kennedy et al. 1996).

Previous studies investigating the relationship between religiosity and health have focused on four dimensions of religion (e.g., George et al. 2002; Idler et al. 2003): religious affiliation or membership (i.e., being a Catholic, Protestant, etc.; e.g., Kennedy et al. 1996), public religious participation (i.e., attending formal services or activities; e.g., Idler and Kasl 1997), private religious practices (such as prayer or meditation; e.g., Ai et al. 2002), and religious coping (the extent to which individuals turn to religion when coping with problems; 
e.g., Krause et al. 2001). Considerable efforts have been made to identify the mechanisms through which these various form of religious involvement may influence people's physical and mental well-being (see Ellison and Levin, 1998, for an overview). Major effects are suggested to result from more favorable health behavior and practices among those being religiously involved, from greater social integration and support within religious communities, as well as from greater psychological and coping resources (see also George et al. 2002).

The scope of our study is limited to private religious activities, which we measure by the individual's self-reported frequency of prayer. Prayer has been shown to measure the broader dimension of 'religiosity' for different religious groups and across European countries as well as, for example, church attendance does (Wolf 2005: 288f.). Moreover, prayer has often been reported to be the most common form of religious practice (e.g., Krause 2004) and in U.S. national samples at least one third of the adult respondents reported to use prayer for health concerns (e.g., Bearon and Koenig 1990; Bell et al. 2005; McCaffrey et al. 2004). Studies suggest that prayer or other private religious activities may be associated with better health outcomes and prolonged survival (e.g., Helm et al. 2000; Meisenhelder and Chandler 2001). It is argued that much of the positive effect of prayer or religiosity on health is mediated through optimism and hope, which improves individuals' capability to cope with illness (e.g., Ai et al. 2002; Van Ness and Larson 2002; Weaver and Flannelly 2004). Also, Krause (2003), for example, reports positive effects of praying for others, which is suggested to enhance positive self-feelings (see Byrd, 1988, for further evidence of positive health outcomes resulting from intercessory prayer). Still, although a substantial amount of "research shows that prayer may enhance the health of those who are significantly ill, [...] it fails to provide a convincing explanation for why this may be so.” (Krause 2004: 1219) 


\section{Method}

The data for this study are drawn from the first public release version of the 2004 'Survey of Health, Aging and Retirement in Europe' (SHARE; for an overview see Börsch-Supan et al. 2005). SHARE is modeled closely after the U.S. 'Health and Retirement Study' and it is the first data set to combine extensive cross-national information on socio-economic status, health, and family relationships of Europe's elder population. Release 1 of the data contains information from some 22,000 computer assisted personal interviews (CAPI) with individuals aged 50 and older in 10 countries: Sweden, Denmark, Germany, the Netherlands, France, Switzerland, Austria, Italy, Spain, and Greece. Our analytic sample does not include France, though, because information on the respondents' frequency of prayer was not collected in this country.

Probability samples were drawn in each participating country. However, the institutional conditions with respect to sampling in the participating countries are so different that a uniform sampling design for the entire project was infeasible. As a result the sampling designs used vary from a simple random selection of households (in the Danish case, for example, from the country's central population register) to rather complicated multi-stage designs (as, for example, in Greece, where the telephone directory was used as a sampling frame). The weighted average household response rate in the face-to-face part of the survey is $62 \%$ (a thorough description of methodological issues is contained in Börsch-Supan and Jürges 2005). Because the information about one's frequency of prayer is collected in SHARE's self-completion questionnaire, the analysis is restricted to those who participated in this part of the survey ( $=81 \%$ of all respondents), which leaves us with a total of slightly less than 14,500 observations for our study.

Altogether, four binary health status variables will be used as left-hand side ('dependent') variables in our logistic regression models. These variables have been 
generated from the SHARE raw data by the SHARE working groups on physical and mental health and are provided with the public release version of the data. First, the originally five answer categories of the self-perceived general health variable - ranging from 'excellent' to 'poor' - were recoded into a new variable that equals 1 , if the respondent reports less than 'very good' health, 0 otherwise. Second, our general physical health variable is coded 1, if the respondent reports to suffer from two or more chronic conditions (such as heart problems, high blood cholesterol, diabetes, etc.), 0 otherwise. Third, functional limitations are coded 1 , if one or more ADL (e.g. problems with eating, bathing, dressing) or IADL (e.g. problems with housework, shopping, preparing meals) limitations are reported, 0 otherwise. Fourth, based on the Euro-D scale (cf. Prince et al. 1999), our depression variable is coded 1, if respondents report to have suffered from depressive symptoms during the month before the interview, 0 otherwise.

Control variables cover socio-demographic characteristics (three age categories and sex), socio-economic status (binary indicators of education - derived from the International Standard Classification of Educational Degrees - and income adequacy), family social resources (whether the respondent lives with a partner or has any children still alive), and health behaviors (measures of BMI, physical activities, tobacco and alcohol consumption) of the respondents.

Finally, our main ('explanatory') variable of interest is derived from answers to the question: "Thinking about the present, how often do you pray?", where the originally six answer categories - ranging from 'more than once a day' to 'never' - are collapsed into three categories: '(almost) daily', 'weekly or less often', and 'never'. Descriptive sample statistics for all variables are displayed in Table 1. Observations with missing values (i.e., 'refusals' or 'don't knows') in the right-hand side variables are flagged with indicator variables, which we 
include in all regressions but do not display in the tables. Generally, missing values are only a minor issue here, affecting at most $3 \%$ of the observations in our sample.

[Table 1 about here]

\section{Empirical findings}

\section{Bivariate results}

To begin with, a simple cross-tabulation of respondents' frequency of prayer by country shall inform us, whether regionally distinct 'religious regimes' - whose existence has been suggested in the literature (e.g., Campbell and Curtis 1994; Voas 2004) - might also be reflected in our data. Table 2 clearly shows that three regional clusters can be identified. First the Mediterranean cluster, whose countries exhibit the highest levels of private religious activity in our study. More than half of the Greek respondents, $49 \%$ of the Italians and still $42 \%$ of older Spaniards report '(almost) daily' prayer. Secondly, a more sporadic engagement in prayer, i.e. 'weekly or less often', is observed in Austria (54\%), Germany (44\%), and Switzerland (41\%). And finally, a third group of countries, characterized by high proportions of elders who 'never' pray, consists of Sweden (56\%), Denmark (49\%), and the Netherlands (42\%). Different from the two Scandinavian countries where only $15-20 \%$ of the older population pray daily, about one-third of the Dutch sample reports to pray frequently. While this suggests some kind of 'religious polarization' among the 50+, the Netherlands must still be considered as one of the most secularized countries in Western Europe today (cf. Knippenberg 1998). With one exception - the Netherlands - our grouping of the nine SHARE countries in 'high', 'medium', and 'low' religiosity areas is congruent with the three distinct regions identified by Voas (2004), for example, on the basis of their predominant religious denomination(s): the 'mixed' Franco-German core (Austria, Germany, the 
Netherlands, and Switzerland), the Catholic fringe (Italy, Spain, and - though Orthodox Greece), and the Protestant but relatively secular Northern fringe (Denmark and Sweden).

[Table 2 about here]

In the next - still bivariate descriptive - step of analysis for the full SHARE sample, we run pooled logistic regressions of 'prayer' on the four health indicators described above (see Table 3). Each of the health variables is significantly correlated $(p<.01)$ with individuals' frequency of prayer. Having in mind findings of previous research, though, the direction of the association is seemingly counterintuitive: on all dimensions, individuals fare worse the more frequently they pray. However, one must keep in mind that this cross-sectional correlation cannot be interpreted as evidence for a negative causal impact of religiosity on health (see the concluding section for a discussion). Next we investigate, whether the observed bivariate associations will hold once we control for other health related individual characteristics in a multivariate model, and whether the strength and direction of the correlations varies across the regional clusters identified above.

[Table 3 about here]

\section{Multivariate results}

The outcome of our control variables in the pooled sample, which we will discuss first, is generally as could be expected from previous studies of elders' physical and mental health (Table 4; for recent analyses using the SHARE data, for example, see Avendano et al 2005; Mackenbach et al. 2005; Dewey and Prince 2005). On all four dimensions covered in our study, health declines significantly with the respondents' age and women's health is usually 
poorer than that of men. Higher levels of education and an adequate income to make ends meet are positively correlated with better health outcomes. There is no straightforward relationship between health and our measures of family social resources. A high BMI and physical inactivity are both clearly associated with poorer health outcomes, while the results for smoking and alcohol consumption are ambiguous or not statistically significant, respectively.

Turning to our 'explanatory' variable - frequency of prayer - the multivariate regression confirms the results of the bivariate analysis. The observed coefficients indicate that respondents who pray (almost) daily are more likely to report less than very good health $(\mathrm{OR}=1.38 ; p<.01)$, to suffer from chronic conditions $(\mathrm{OR}=1.14 ; p<.01)$ or functional limitations $(\mathrm{OR}=1.15 ; p<.05)$, and to exhibit symptoms of depression $(\mathrm{OR}=1.26 ; p<.01)$ than their counterparts who never pray. Significant differences between the latter (reference) group and individuals who pray occasionally, i.e. 'weekly or less often', only remain, however, if the probability to perceive one's own health as less than very good $(\mathrm{OR}=1.11 ; p$ $<.05)$ is considered.

[Table 4 about here]

When estimating separate multivariate models for each of the regions identified in Table 2 as having 'low', 'medium' or 'high' levels of religiosity, the previously statistically significant association of prayer with the four health outcomes in our analysis tends to disappear (see Table 5), probably as a result of the substantially lower sample size in each single regression. Still, a significantly negative correlation between (almost) daily prayer and functional limitations is found in southern Europe (Greece, Italy, and Spain; OR $=1.32 ; p<$ .01 ), whereas a negative relationship with general physical health, i.e. chronic conditions, is 
observed in the northern European countries (Denmark, Sweden, and The Netherlands; OR = $1.60 ; p<.01)$. Self-perceived health turns out to bear no significant association with prayer in the 'medium' group of countries (Austria, Germany, and Switzerland) only, while elevated risks of less than 'very good' health among those praying frequently are observed elsewhere. $\chi^{2}$-tests comparing the coefficients of the explanatory variables in each of the models suggest that the negative religion-health nexus observed on the self-perceived and general physical health dimensions is strongest in the southern, i.e. most religious countries $(p<.05)$.

[Table 5 about here]

\section{Discussion}

Exploiting the 2004 'Survey of Health, Ageing and Retirement in Europe', this paper is the first to provide a comprehensive investigation of the relationship between private religious involvement and various dimensions of older adults' physical and mental health in a representative sample of older adults from nine continental European countries.

Our empirical findings are clear: even when controlling for a large array of potentially confounding variables, we detect a statistically significant negative correlation between individuals' frequency of prayer and all four health outcomes in the analysis. Moreover, although we identified three distinct regional clusters of 'low', 'medium', and 'high' levels of religiosity - following a north-south gradient - only minor systematic variation in the individual-level prayer-health nexus across these diverse contexts is observed: in the Mediterranean countries, which exhibit the highest shares of elders who pray (almost) daily, the negative association between private religious involvement and self-reports of poor health or chronic conditions is stronger than elsewhere in Europe. What drives these results remains an open research question for future studies. 
The cross-sectional evidence from SHARE is less contradictory to related U.S. evidence than it might appear at first glance. Despite the frequently portrayed positive relationship between greater religiosity and better health outcomes, the picture quickly becomes ambiguous if one turns to specific studies and associations between particular dimensions of religion and health. Meisenhelder and Chandler (2001: 327; italics not in the original), for example, note that it is "a generally accepted axiom [...] that people turn to God in their hour of need. Thus, if physical health impacted frequency of prayer, the results would likely show frequency of prayer related to poorer health, not better perceived general health [...]."Also, not many studies investigated the relationship between prayer and depression for the older U.S. population in particular. We are reluctant to follow McCullough and Larson's (1999) finding of no apparent association between private religious activities and measures of depression, because this is based on studies for the general population and at least our own findings for Europe indicate that this relationship might be more significant among elders (but see Koenig et al. 1998).

The present study has two obvious limitations. First, while our analysis accounts well for various dimensions of people's health, its measure of religiosity is limited to one specific private religious activity. Although the use of church membership and attendance, for example, is not without methodological problems (e.g., Flannelly et al. 2004; Wolf 2005), including the public sphere of religiosity would add substantially to a more comprehensive account of the religion-health connection in Europe (see also Idler et al. 2003). Second, although SHARE is designed to become a panel study (cf. Boersch-Supan et al. 2005: Chapter 1), the currently available data are yet cross-sectional. Thus, no statements about any causal relationships underlying the observed negative correlations between prayer and selfperceived general health or depression can be made. Does poor health impact greater religiosity as persons seek solace and comfort (e.g., Larson and Koenig 2001: 70), or does a 
"potential dark side of religion" (e.g. religious doubt; Krause 2004: 1219f.) harm individuals' well-being? A longitudinal study might even reveal a positive association between prayer and health outcomes, including mortality (e.g., Helm et al. 2000). Although much further research needs to be done - particularly with regard to a better theoretical understanding of the mechanisms driving the religion-health nexus - the evidence presented here nevertheless suggests that religion deserves to be considered in future health studies and continues to be a relevant factor in the (longer and healthier) lives of Europe's aging populations in the $21^{\text {st }}$ century.

\section{Acknowledgements}

We are grateful for comments by Hendrik Jürges and Martin Salm. This paper is based on data from the early Release 1 of SHARE 2004, which is preliminary and may contain errors that will be corrected in later releases. The SHARE data collection has been primarily funded by the European Commission through the $5^{\text {th }}$ framework program (project QLK6-CT-200100360 in the thematic program 'Quality of Life'). Additional funding came from the U.S. National Institute on Aging (U01 AG09740-13S2, P01 AG005842, P01 AG08291, P30 AG12815, Y1-AG-4553-01 and OGHA 04-064). Data collection in Austria (through the Austrian Science Fund, FWF) and Switzerland (through BBW/OFES/UFES) was nationally funded.

\section{References}

Ai, Amy L., Christopher Peterson, Steven F. Bolling, and Harold Koenig. 2002. "Private Prayer and Optimism in Middle-Aged and Older Patients Awaiting Cardiac Surgery." The Gerontologist 42: 70-81. 
Ainlay, Stephen C., Royce Singleton Jr., and Victoria L. Swigert. 1992. "Aging and Religious Participation: Reconsidering the Effects of Health." Journal for the Scientific Study of Religion 31: 175-188.

Aukst-Margetic, Branka, and Branimir Margetic. 2005. "Religiosity and Health Outcomes: Review of Literature." Collegium Antropologicum 29: 365-371.

Avendano, M. / Aro, A.R. / Mackenbach, J. (2005): "Socio-Economic Disparities in Physical Health in 10 European Countries.” In A. Börsch-Supan et al. (eds.), Health, Ageing and Retirement in Europe - First Results from the Survey of Health, Ageing and Retirement in Europe, Mannheim: MEA, 89-94.

Bearon, Lucille B., and Harold G. Koenig. 1990. "Religious Cognitions and Use of Prayer in Health and Illness." The Gerontologist 30, 249-253.

Bell, Ronny A., Cynthia Suerken, Sara A. Quandt, Joseph G. Grzywacz, Wei Lang, and Thomas A. Arcury. 2005. "Prayer for Health among U.S. Adults: The 2002 National Health Interview Survey." Complementary Health Practice Review 10: 175-188.

Benjamins, Maureen Reindl. 2004. "Religion and Functional Health Among the Elderly: Is There a Relationship and Is It Constant?" Journal of Aging and Health 16: 355-374.

Benjamins, Maureen Reindl, Marc A. Musick, Deborah T Gold, and Linda K. George. 2003. “Age-Related Declines in Activity Level: The Relationship Between Chronic Illness and Religious Activities." Journals of Gerontology Series B - Social Sciences 58: S377-S385.

Börsch-Supan, Axel, Agar Brugiavini, Hendrik Jürges, Johan Mackenbach, Johannes Siegrist, and Guglielmo Weber. eds. 2005. Health, Ageing and Retirement in Europe First results from the Survey of Health, Ageing and Retirement in Europe. Mannheim: Mannheim Research Institute for the Economics of Aging, available at http://www.share-project.org. 
Börsch-Supan, A., and Hendrik Jürges. eds. 2005. The Survey of Health, Ageing and Retirement in Europe - Methodology. Mannheim: Mannheim Research Institute for the Economics of Aging, available at http://www.share-project.org.

Byrd, Randolph C. 1988. "Positive Therapeutic Effects Intercessory Prayer in a Coronary Care Unit Population.” Southern Medical Journal 81: 826-829.

Campbell, Robert A., and James E. Curtis. 1994. "Religious Involvement across Societies: Analyses for Alternative Measures in National Surveys." Journal for the Scientific Study of Religion 33: 215-229.

Cederblad, Marianne, L. Dahlin, O. Hagnell, and K. Hansson. 1995. "Coping with Life Span Crises in a Group at Risk of Mental and Behavioral Disorders: From the Lundby Study." Acta Psychiatrica Scandinavia 91: 322-330.

Dewey, Michael, and Martin J. Prince (2005): "Mental Health.” In A. Börsch-Supan et al. (eds.), Health, Ageing and Retirement in Europe - First Results from the Survey of Health, Ageing and Retirement in Europe, Mannheim: MEA, 108-117.

Ellison, Christopher G., and Jeffrey S. Levin. 1998. "The Religion-Health Connection: Evidence, Theory, and Future Directions." Health Education \& Behavior 25: 700-720.

Flannelly, Kevin J., Christopher G. Ellison, and Adrienne L. Strock. 2004. "Methodologic Issues in Research on Religion and Health.” Southern Medical Journal 97: 1231-1241.

George, Linda K., Christopher G. Ellison, and David B. Larson. 2002. "Explaining the Relationships Between Religious Involvement and Health." Psychological Inquiry 13: 190-200.

Greeley, Andrew M. 2003. Religion in Europe at the End of the Second Millennium: A Sociological Profile. New Brunswick, NJ: Transaction Publishers.

Hackney, Charles B., and Glenn S. Sanders. 2003. "Religiosity and Mental Health: A MetaAnalysis of Recent Studies.” Journal for the Scientific Study of Religion 42: 43-55. 
Helm, Hughes M., Judith C. Hays, Elizabeth P. Flint, Harold G. Koenig, and Dan G. Blazer. 2000. "Does Private Religious Activity Prolong Survival? A Six-Year Follow-up Study of 3,851 Older Adults." Journals of Gerontology Series A - Medical Sciences 55: M400-M405.

Idler, Ellen L. 1987. "Religious Involvement and the Health of the Elderly: Some Hypotheses and an Initial Test.” Social Forces 66: 226-238.

Idler, Ellen L., and Stanislav V. Kasl. 1992. "Religion, Disability, Depression, and the Timing of Death.” American Journal of Sociology 97: 1052-1079.

Idler, Ellen L., and Stanislav V. Kasl. 1997. "Religion among Disabled and Nondisabled Persons II: Attendance at Religious Services as a Predictor of the Course of Disability." Journals of Gerontology Series B - Social Sciences 52: S306-S316.

Idler, Ellen L., Marc A. Musick, Christopher G. Ellison, Linda K. George, Neal Krause, Marcia G. Ory, Kenneth I. Pargament, Lynda H. Powell, Lynn G. Underwood, and David R. Williams. 2003. "Measuring Multiple Dimensions of Religion and Spirituality for Health Research.” Research on Aging 25: 327-365.

Kelley-Moore, Jessica A., and Kenneth F. Ferraro. 2001. "Functional Limitations and Religious Service Attendance in Later Life: Barrier and/or Benefit Mechanism?" Journals of Gerontology Series B - Social Sciences 56: S365-S373.

Kennedy, Gary J., Howard R. Kelman, Cynthia Thomas, and Jiming Chen. 1996. "The Relation of Religious Preference and Practice to Depressive Symptoms among 1,855 Older Adults.” Journals of Gerontology Series B - Psychological Sciences 51: P301P308.

Knippenberg, Hans. 1998. "Secularization in the Netherlands in Its Historical and Geographical Dimensions." GeoJournal 45: 209-220, 
Koenig, Harold G. 2004. "Religion, Spirituality, and Medicine: Research Findings and Implications for Clinical Practice.” Southern Medical Journal 97: 1194-1200.

Koenig, Harold G., Linda K. George, and Bercedis L. Peterson. 1998. "Religiosity and Remission of Depression in Medically Ill Older Patients." American Journal of Psychiatry 155: 536-542.

Koenig, Harold G., and David B. Larson. 2001. "Religion and Mental Health: Evidence for an Association.” International Review of Psychiatry 13: 67-78.

Krause, Neal. 2003. "Praying for Others, Financial Strain, and Physical Health Status in Late Life." Journal for the Scientific Study of Religion 42: 377-391.

Krause, Neal. 2004. "Religion, Aging, and Health: Exploring New Frontiers in Medical Care." Southern Medical Journal 97: 1215-1222.

Krause, Neal, Christopher G. Ellison, Benjamin A. Shaw, John P. Marcum, and Jason D. Boardman. 2001. "Church-Based Social Support and Religious Coping.” Journal for the Scientific Study of Religion 40: 637-656.

la Cour, Peter, Kirsten Avlund, and Kirsten Schultz-Larsen. 2006. "Religion and Survival in a Secular Region. A Twenty Year Follow-up of 734 Danish Adults Born in 1914." Social Science \& Medicine 62:157-164.

Mackenbach, J. / Avendano, M. / Andersen-Ranberg, K. / Aro, A.R. (2005): "Physical Health.” In A. Börsch-Supan et al. (eds.), Health, Ageing and Retirement in Europe First Results from the Survey of Health, Ageing and Retirement in Europe, Mannheim: MEA, 82-88.

McCaffrey, Anne M., David M. Eisenberg, Anna T. R. Legedza, Roger B. Davis, and Russel S. Phillips. 2004. "Prayer for Health Concerns." Archives of Internal Medicine 164: 858-862. 
McCullough, Michael E., and David B. Larson. 1999. "Religion and Depression: A Review of the Literature." Twin Research 2, 126-136.

McFadden, Susan H. 1995. "Religion and Well-Being in Aging Persons in an Aging Society.” Journal of Social Issues 51: 161-175.

Meisenhelder, Janice B., and Emily N. Chandler. 2001. "Frequency of Prayer and Functional Health in Presbyterian Pastors.” Journal for the Scientific Study of Religion 40: 323329.

Norton, Maria C., Ingmar Skoog, Lynn M. Franklin, Christopher Corcoran, JoAnn T. Tschanz, Peter P. Zandi, John C.S. Breitner, Kathleen A. Welsh-Bohmer, and David C. Steffens for the Cache County Investigators. 2006. "Gender Differences in the Association Between Religious Involvement and Depression: The Cache County (Utah) Study.” Journals of Gerontology Series B - Psychological Sciences 61: P129-P136.

Prince, Martin J., Reischies, F., Beekman, A.T., Fuhrer, R., Jonker, C., Kivela, S.L., Lawlor, B.A., Lobo, A., Magnusson, H., Fichter, M., van Oyen, H., Roelands, M., Skoog, I., Turrina, C. and Copeland, J.R. 1999. "Development of the EURO-D Scale - A European Union Initiative to Compare Symptoms of Depression in 14 European Centres.” British Journal of Psychiatry 174: 330-338.

Princeton Religious Research Center. 1999. "Index of Leading Religious Indicators at Highest Point in 13 Years.” Emerging Trends 21: 1

Ringdal, Gerd I. 1996. "Religiosity, Quality of Life, and Survival in Cancer Patients.” Social Indicators Research 38: 193-211.

Van Ness, Peter H., and David B. Larson. 2002. "Religion, Senescence, and Mental Health." American Journal of Geriatric Psychiatry 10: 386-397. 
Voas, David. 2004. "Religion in Europe: One theme, many variations?" Unpublished manuscript, downloaded from http://www.religionomics.com/erel/S2-Archives/ REC04/Voas\%20-\%20Religion\%20in\%20Europe\%20ver.\%202.pdf [Nov. 2006].

Weaver, Andrew J., and Kevin J. Flannelly. 2004. "The Role of Religion/Spirituality for Cancer Patients and Their Caregivers." Southern Medical Journal 97: 1210-1214.

Weaver, Andrew J., Kevin J. Flannelly, and David B. Case. 2004. "Religion and Spirituality in Three Major General Medical Journals From 1998 to 2000.” Southern Medical Journal 97: 1245-1249.

Weaver, Andrew J., Laura .T. Flannelly, Adrienne L. Strock, Neal Krause, and Kevin J. Flannelly. 2005. "The Quantity and Quality of Research on Religion and Spirituality in Four Major Gerontology Journals Between 1985 and 2002.” Research on Aging 27: 119-135.

Wolf, C. 2005. "Measuring Religious Affiliation and Religiosity in Europe.” In J.H.P. Hoffmeyer-Zlotnik and Janet Harkness (eds.), Methodological Aspects in CrossNational Research (ZUMA-Nachrichten Spezial 11), Mannheim: ZUMA, 279-294. 


\section{Tables}

Table 1: Pooled descriptive sample statistics

Variable

Unweighted mean (standard deviation)

Frequency of prayer

'(almost) daily'

'weekly or less often'

'never'

Health status

Less than 'very good' self-perceived general health

General physical health $-2+$ chronic diseases

$1+$ functional limitations

Symptoms of depression

Demographics \& SES

Age $50-64$

Age $65-74$

Age 75+

Female

Low education

Medium education

High education

Easy to make ends meet ${ }^{\mathrm{a}}$

Social resources

Living with partner

Any children alive 
Table 1 (cont'd.): Pooled descriptive sample statistics Variable

Health behaviors

Body Mass Index

Physically inactive

.08

Current smoker

Former smoker

Never smoker

$>2$ glasses of alcohol per day .12

Notes: ${ }^{a}$ This variable is based on the item "Thinking about your household's total monthly income, would you say that your household is able to make ends meet ..." and is coded 1, if the respondent answered 'fairly easily or easily', 0 otherwise. ${ }^{\mathrm{b}}$ This variable is coded 1 , if the respondent answered 'hardly ever or never' to the question: "How often do you engage in vigorous physical activity, such as sports, heavy housework, or a job that involves physical labour?", 0 otherwise.

Source: SHARE 2004 (Release 1), authors' calculations. 
Table 2: Frequency of prayer among the 50+ in nine European countries (in percent)

Frequency of prayer

‘(almost) daily' 'weekly or less often' 'never'

Countries with 'high' levels of

religiosity

Greece $(\mathrm{n}=1,810)$

53.5

40.4

6.0

Italy $(\mathrm{n}=1,451)$

49.4

34.8

15.8

Spain $(\mathrm{n}=1,527)$

41.7

38.0

20.3

Countries with 'medium' levels

of religiosity

Austria $(\mathrm{n}=1,673)$

25.6

54.3

20.1

Germany $(\mathrm{n}=1,845)$

20.5

44.3

35.2

Switzerland $(n=676)$

36.6

41.4

22.0

Countries with 'low' levels of

religiosity

Denmark $(\mathrm{n}=1,136)$

21.1

29.9

49.0

Sweden $(\mathrm{n}=2,050)$

14.2

30.2

55.6

The Netherlands $(\mathrm{n}=1,980)$

34.8

23.6

41.6

All countries $(n=14,148)$

32.5

37.1

30.4

Source: SHARE 2004 (Release 1), weighted percentages, authors' calculations. Missing values (= 2.5 percent of the total sample) are excluded. 
Table 3: Results of pooled bivariate logistic regressions of 'prayer' on various health outcomes - odds ratios (standard errors)

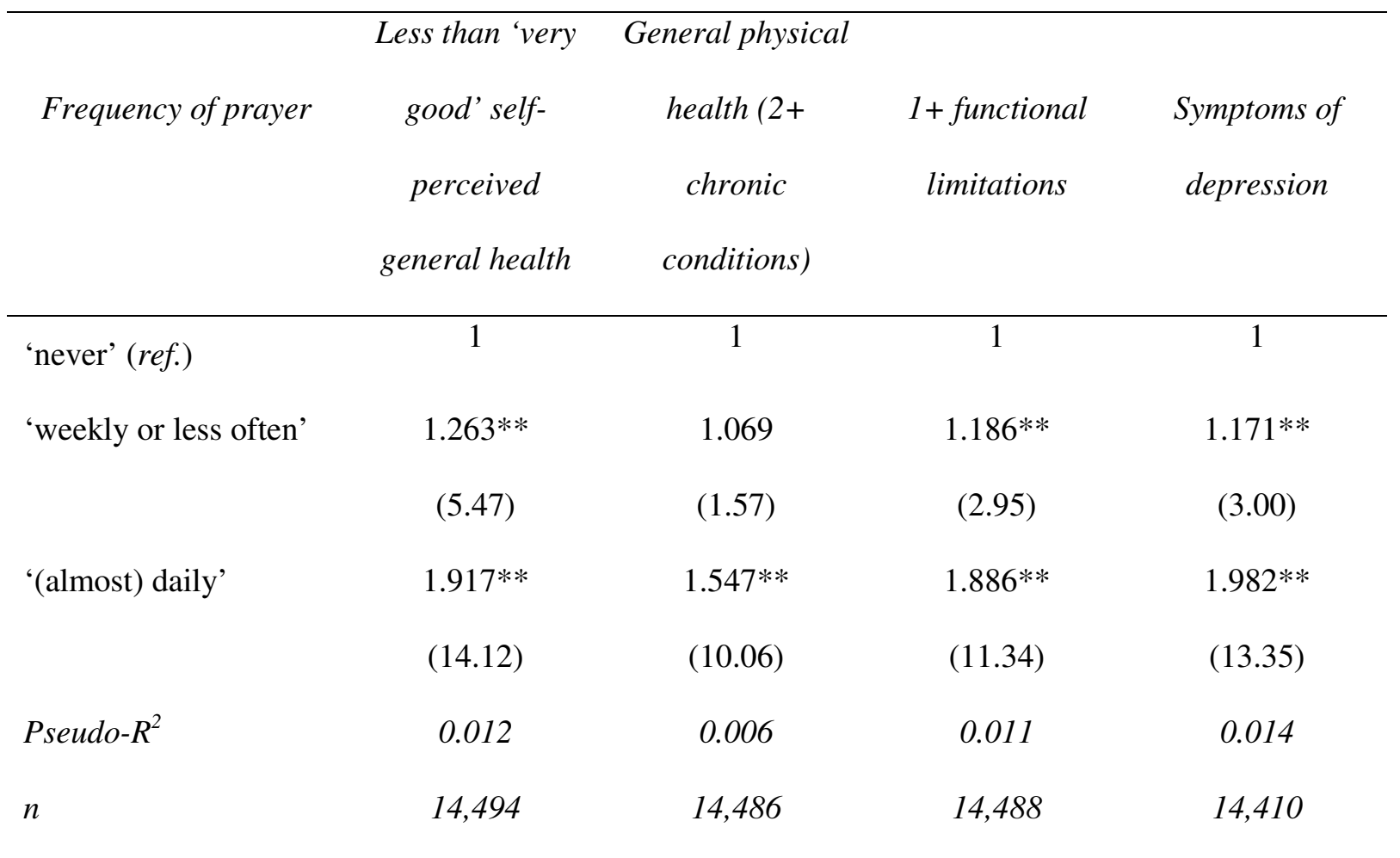

Source: SHARE 2004 (Release 1), authors' calculations. Missing value indicator variables are not displayed. ${ }^{*} p<.05 .{ }^{*} p<.01$. 
Table 4: Results of pooled multivariate logistic regressions for various health outcomes odds ratios (standard errors)

$\begin{array}{cccc}\text { Less than 'very } & \text { General physical } & & \\ \text { good' self- } & \text { health }(2+ & 1+\text { functional } & \text { Symptoms of } \\ \text { perceived } & \text { chronic } & \text { limitations } & \text { depression } \\ \text { general health } & \text { conditions }) & & \end{array}$

Frequency of prayer

'never' (ref.)

1

1

1

1

'weekly or less often'

$1.109 *$

0.954

0.997

0.971

(2.26)

(1.05)

(0.04)

(0.53)

‘(almost) daily’

$1.383 * *$

$1.139 * *$

$1.148 *$

$1.258 * *$

(6.37)

(2.69)

(2.14)

Demographics \& SES

Age 50 - 64 (ref.)

Age 65-74

$1.644 * *$

(11.12)

$1.728 * *$

1.004

(17.86)

(9.41)

(0.08)

Age 75+

$2.704 * *$

$3.177 * *$

$3.716^{* *}$

$1.337 * *$

(15.78)

(21.85)

(20.65)

Female

$1.191^{* *}$

$1.293^{* *}$

$1.445^{* *}$

$2.103 * *$

$$
\text { (4.21) }
$$

(6.33)

(6.63)

(15.00)

Low education (ref.)

\section{1}

1

Medium education

$0.723 * *$

$0.829 * *$

$0.726^{* *}$

$0.740 * *$

(7.32)

(4.41)

(5.53)

High education

$0.491 * *$

$0.784 * *$

$0.604 * *$

$0.653 * *$

(13.87)

(4.65)

(6.51)

(6.46)

Easy to make ends meet

$0.630 * *$

$0.785^{* *}$

$0.730 * *$

$0.539 * *$

(10.72)

(6.15)

(6.20)

(13.82) 
Table 4 (cont'd.): Results of pooled multivariate logistic regressions for various health outcomes - odds ratios (standard errors)

\begin{tabular}{|c|c|c|c|c|}
\hline & $\begin{array}{l}\text { Less than 'very } \\
\text { good' self- } \\
\text { perceived } \\
\text { general health }\end{array}$ & $\begin{array}{c}\text { General } \\
\text { physical health } \\
(2+\text { chronic } \\
\text { conditions })\end{array}$ & $\begin{array}{c}1+\text { functional } \\
\text { limitations }\end{array}$ & $\begin{array}{c}\text { Symptoms of } \\
\text { depression }\end{array}$ \\
\hline Social resources & & & & \\
\hline Living with partner & $\begin{array}{l}1.062 \\
(1.26)\end{array}$ & $\begin{array}{l}0.919 \\
(1.93)\end{array}$ & $\begin{array}{c}0.735 * * \\
(5.65)\end{array}$ & $\begin{array}{c}0.782 * * \\
(4.98)\end{array}$ \\
\hline Any children alive & $\begin{array}{l}0.913 \\
(1.44)\end{array}$ & $\begin{array}{l}1.185^{* *} \\
(2.82)\end{array}$ & $\begin{array}{l}1.032 \\
(0.41)\end{array}$ & $\begin{array}{l}1.029 \\
(0.41)\end{array}$ \\
\hline Health behaviors & & & & \\
\hline Body Mass Index & $\begin{array}{l}1.073 * * \\
(14.05)\end{array}$ & $\begin{array}{l}1.077 * * \\
(16.67)\end{array}$ & $\begin{array}{c}1.034 * * \\
(6.16)\end{array}$ & $\begin{array}{l}1.011 * \\
(2.35)\end{array}$ \\
\hline Physically inactive & $\begin{array}{l}4.573 * * \\
(13.10)\end{array}$ & $\begin{array}{c}1.655 * * \\
(7.53)\end{array}$ & $\begin{array}{l}5.133 * * \\
(23.94)\end{array}$ & $\begin{array}{l}3.230 * * \\
(17.49)\end{array}$ \\
\hline Current smoker & $\begin{array}{l}1.119 * \\
(2.06)\end{array}$ & $\begin{array}{c}0.739 * * \\
(5.64)\end{array}$ & $\begin{array}{l}0.981 \\
(0.26)\end{array}$ & $\begin{array}{l}0.965 \\
(0.56)\end{array}$ \\
\hline Former smoker (ref.) & 1 & 1 & 1 & 1 \\
\hline Never smoker & $\begin{array}{l}0.977 \\
(0.51)\end{array}$ & $\begin{array}{c}0.746 * * \\
(6.64)\end{array}$ & $\begin{array}{l}0.892 \\
(1.90)\end{array}$ & $\begin{array}{c}0.863 * * \\
(2.76)\end{array}$ \\
\hline $2+$ glasses of alcohol & $\begin{array}{l}1.011 \\
(0.20)\end{array}$ & $\begin{array}{l}0.938 \\
(1.12)\end{array}$ & $\begin{array}{c}0.792 * * \\
(2.83)\end{array}$ & $\begin{array}{l}0.950 \\
(0.73)\end{array}$ \\
\hline Pseudo-R2 & 0.10 & 0.08 & 0.15 & 0.09 \\
\hline$n$ & 14,494 & 14,486 & 14,488 & 14,410 \\
\hline
\end{tabular}

Source: SHARE 2004 (Release 1), authors' calculations. Missing value indicator variables are not displayed. Observations with missing values for health status variables excluded.

$* p<.05 . * * p<.01$. 
Table 5: Results of separate multivariate logistic regressions for countries with 'low', 'medium', and 'high' levels of religiosity - odds ratios (standard errors)

\begin{tabular}{cccc}
\hline Less than 'very & General & & \\
good' self- & physical health & $1+$ functional & Symptoms of \\
perceived & $(2+$ chronic & limitations & depression \\
general health & conditions $)$ & & \\
\hline
\end{tabular}

Countries with 'low' level of

religiosity ${ }^{\mathrm{a}}$ - frequency of prayer

'weekly or less often'

$1.074_{d}$

1.021

1.202

1.018

$(1.86)$

'(almost) daily'

$1.345_{\mathrm{d}} * *$

0.998

$1.315^{* *}$

1.174

(3.80)

$(0.03)$

(2.69)

Pseudo-R ${ }^{2}$

0.08

0.07

0.14

0.06

$n$

5,317

5,314

5,314

5,274

Countries with 'medium' level of

religiosity ${ }^{\mathrm{b}}$ - frequency of prayer

'never' (ref.)

1

1

1

1

'weekly or less often'

$0.856_{\text {e }}$

$0.914_{\mathrm{e}}$

1.105

0.975

'(almost) daily'

$1.070_{\mathrm{e}}$

$0.999_{\text {e }}$

1.256

1.089

$(0.64)$

$(0.01)$

(1.67)

Pseudo-R ${ }^{2}$

0.10

0.07

0.19

0.09

$n$

4,292

4,292

4,290

4,272

Continued next page ... 
Table 5 (cont'd.): Results of separate multivariate logistic regressions for countries with 'low', 'medium', and 'high' levels of religiosity - odds ratios (standard errors)

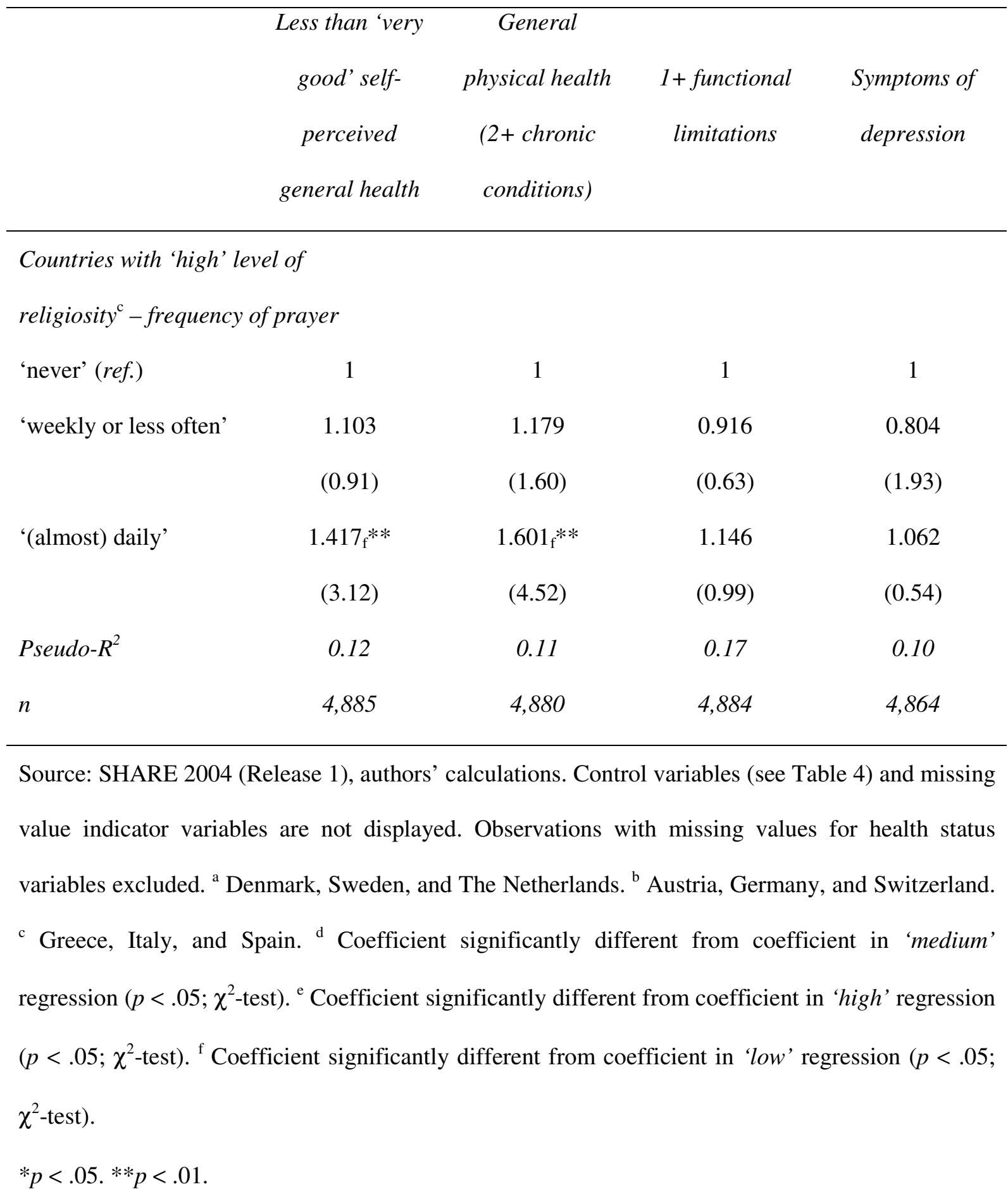




\section{Discussion Paper Series}

Mannheim Research Institute for the Economics of Aging Universität Mannheim

To order copies, please direct your request to the author of the title in question.

\begin{tabular}{|c|c|c|c|}
\hline Nr. & Autoren & Titel & Jahr \\
\hline $103-06$ & $\begin{array}{l}\text { Dirk Krueger } \\
\text { Alexander Ludwig }\end{array}$ & $\begin{array}{l}\text { On the Consequences of Demographic Change } \\
\text { for Rates of Returns to Capital, and the } \\
\text { Distribution of Wealth and Welfare }\end{array}$ & 06 \\
\hline $104-06$ & $\begin{array}{l}\text { Karsten Hank, } \\
\text { Hendrik Jürges, } \\
\text { Jürgen Schupp, } \\
\text { Gert G. Wagner }\end{array}$ & $\begin{array}{l}\text { Die Messung der Greifkraft als objektives } \\
\text { Gesundheitsmaß in sozialwissenschaftlichen } \\
\text { Bevölkerungsumfragen: Erhebungsmethodische } \\
\text { und inhaltliche Befunde auf der Basis von } \\
\text { SHARE und SOEP }\end{array}$ & 06 \\
\hline $105-06$ & Hendrik Jürges & $\begin{array}{l}\text { True health vs. response styles: Exploring cross- } \\
\text { country differences in self-reported health }\end{array}$ & 06 \\
\hline $106-06$ & $\begin{array}{l}\text { Christina Benita } \\
\text { Wilke }\end{array}$ & $\begin{array}{l}\text { Die ökonomischen Auswirkungen des } \\
\text { demographischen Wandels in Bayern }\end{array}$ & 06 \\
\hline $107-06$ & Barbara Berkel & $\begin{array}{l}\text { Retirement Age and Preretirement in German } \\
\text { Administrative Data }\end{array}$ & 06 \\
\hline $108-06$ & $\begin{array}{l}\text { Hans-Martin von } \\
\text { Gaudecker } \\
\text { Carsten Weber }\end{array}$ & $\begin{array}{l}\text { Mandatory Unisex Policies and Annuity Pricing: } \\
\text { Quasi-Experimental Evidence from Germany }\end{array}$ & 06 \\
\hline $109-06$ & Daniel Schunk & $\begin{array}{l}\text { The German SAVE Survey: Documentation and } \\
\text { Methodology }\end{array}$ & 06 \\
\hline $110-06$ & Barbara Berkel & $\begin{array}{l}\text { THE EMU and German Cross Border Portfolio } \\
\text { Flows }\end{array}$ & 06 \\
\hline $111-06$ & Martin Salm & $\begin{array}{l}\text { Can subjective mortality expectations and stated } \\
\text { preferences explain varying consumption and } \\
\text { saving behaviors among the elderly? }\end{array}$ & 06 \\
\hline $112-06$ & $\begin{array}{l}\text { Daniel Houser, } \\
\text { Daniel Schunk, } \\
\text { Joachim Winter }\end{array}$ & Trust Games Measure Trust & 06 \\
\hline $113-06$ & $\begin{array}{l}\text { Hanming Fang, } \\
\text { Michael Keane, } \\
\text { Ahmed Khwaja, } \\
\text { Martin Salm, } \\
\text { Dan Silverman }\end{array}$ & $\begin{array}{l}\text { Testing the Mechanisms of Structural Models: } \\
\text { The Case of the Mickey Mantle Effect }\end{array}$ & 06 \\
\hline $114-06$ & $\begin{array}{l}\text { Axel Börsch-Supan, } \\
\text { Anette Reil-Held, } \\
\text { Daniel Schunk } \\
\end{array}$ & $\begin{array}{l}\text { Das Sparverhalten deutscher Haushalte: Erste } \\
\text { Erfahrungen mit der Riester-Rente }\end{array}$ & 06 \\
\hline $115-07$ & $\begin{array}{l}\text { Karsten Hank, } \\
\text { Barbara Schaan }\end{array}$ & $\begin{array}{l}\text { Cross-National Variations in the Correlation } \\
\text { between Frequency of Prayer and Health } \\
\text { among Older Europeans }\end{array}$ & 07 \\
\hline
\end{tabular}

